\section{Evidence that thalidomide is effective in recurrent bleeding from watermelon stomach associated with liver cirrhosis}

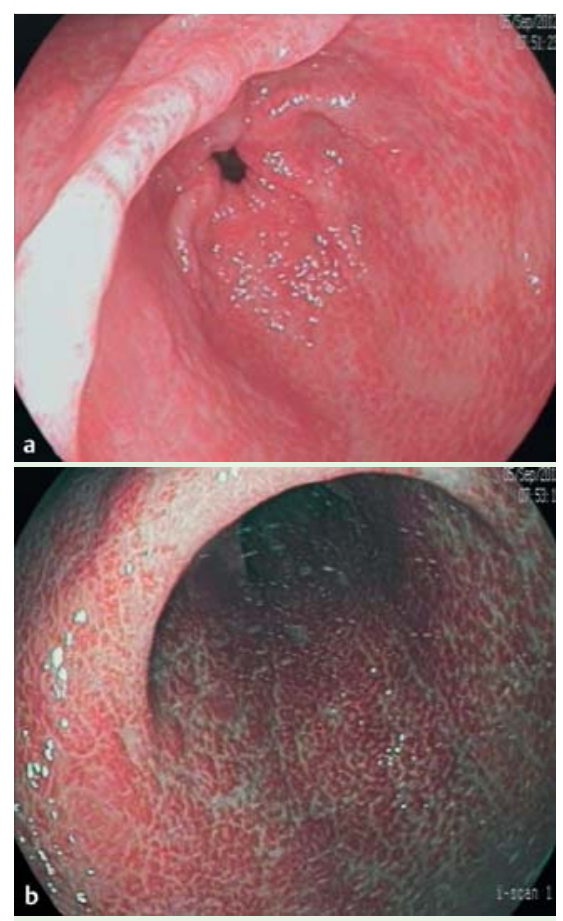

Fig. 1 Pretreatment gastroscopy showing longitudinal rows of reddish stripes radiating from the pylorus into the antrum using: a high-definition white light; b i-Scan 1.

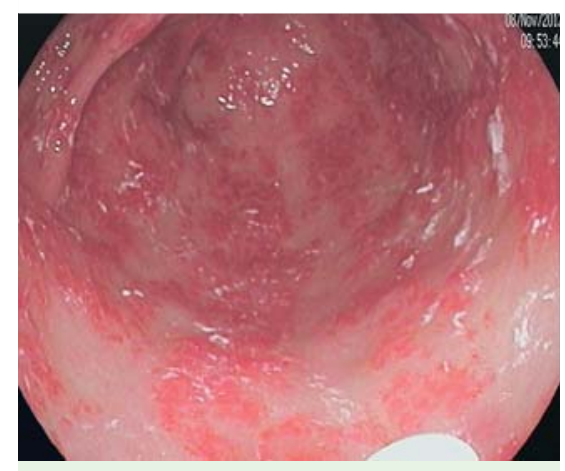

Fig. 2 Gastroscopy after three applications of argon plasma coagulation (APC) showing only a minimal reduction in the number of ectatic mucosal vessels.

Thalidomide has been shown to be effective in preventing bleeding from gastrointestinal vascular malformations that have not responded to endoscopic therapy [1,
2]. However, the efficacy of thalidomide in patients with watermelon stomach associated with liver cirrhosis has not yet been adequately studied and no longterm results have been published [3]. An 88-year-old woman was admitted to hospital for evaluation of recurrent gastrointestinal bleeding. She had a history of hypertension and osteoporosis, and some years previously had been diagnosed as having cryptogenic liver cirrhosis.

Gastroscopy revealed small esophageal varices with no signs of recent bleeding. The most impressive finding was longitudinal rows of reddish stripes radiating from the pylorus into the antrum ( $\bullet$ Fig. 1). A diagnosis of watermelon stomach or gastric antral vascular ectasia (GAVE) was made. After exclusion of other bleeding sources within the gastrointestinal tract by colonoscopy and capsule endoscopy, the ectatic mucosal vessels in the antrum were treated with argon plasma coagulation (APC) using the VIO 200D APC 2 system (Erbe Elektromedizin, Tübingen, Germany) and E6 PRECISE Mode (APC probe 2200C). This treatment was repeated twice during the following weeks because the ectatic mucosal vessels of the antrum rapidly reappeared after APC ( $\bullet$ Fig. 2 ). In each session the aim was to treat nearly all (approximately $90 \%$ ) of the visible vascular lesions.

Despite the use of APC, an average of two units of blood every 2 weeks was needed to maintain the patient's hemoglobin level at about $9 \mathrm{~g} / \mathrm{dL}$. Therefore she was started on thalidomide $50 \mathrm{mg}$ twice daily. After 3 weeks she received a further two units of blood because her hemoglobin level had dropped to $7.5 \mathrm{~g} / \mathrm{dL}$. During further follow-up, however, the patient remained stable and her hemoglobin began to steadily increase.

Treatment with thalidomide was stopped after 4 months. Since that time, the patient has been seen regularly in our outpatient clinic. She has had no further epi- sodes of gastrointestinal bleeding and her last hemoglobin level, having been off treatment for almost a year, was $9.8 \mathrm{~g} / \mathrm{dL}$. This case provides evidence that recurrent bleeding from a watermelon stomach associated with liver cirrhosis, which cannot be managed by APC, can be treated successfully by thalidomide. In our patient long-term remission from gastrointestinal bleeding has been maintained following her 4-month course of thalidomide. We suggest that the efficacy of this treatment approach should be evaluated in randomized trials.

Endoscopy_UCTN_Code_TTT_1AO_2AD

Competing interests: None

\section{Stephan Moser, Alexander Tischer, Asia Karpi, Michael Schleicher, Susanne Stavjanik, Michael Gschwantler}

Department of Internal Medicine IV, Wilhelminenspital, Vienna, Austria

\section{References}

1 Ge ZZ, Chen HM, Gao YJ et al. Efficacy of thalidomide for refractory gastrointestinal bleeding from vascular malformation. Gastroenterology 2011; 141: 1629-1637

2 Kamalaporn P, Saravanan R, Cirocco $M$ et al. Thalidomide for the treatment of chronic gastrointestinal bleeding from angiodysplasias: a case series. Eur J Gastroenterol Hepatol 2009; 21: 1347-1350

3 Garrido Serrano A, León R, Sayago $M$ et al. Thalidomide treatment in cirrhotic patients with severe anemia secondary to vascular malformations. Dig Dis Sci 2012; 57: 1112 1113

\section{Bibliography}

DOI http://dx.doi.org/

10.1055/s-0034-1377369

Endoscopy 2014: 46: E384

(c) Georg Thieme Verlag KG

Stuttgart - New York

ISSN 0013-726X

\section{Corresponding author}

\section{Michael Gschwantler, MD}

Wilhelminenspital

Department of Internal Medicine IV

Montleartstrasse 37

A-1160 Vienna

Austria

Fax: +43-1-491502409

michael.gschwantler@wienkav.at 